\title{
Silicon wafer defect detection using high frequency guided waves
}

\section{Michael Lauper, Paul Fromme, Jean-Luc Robyr, Bernard Masserey}

Michael Lauper, Paul Fromme, Jean-Luc Robyr, Bernard Masserey, "Silicon wafer defect detection using high frequency guided waves," Proc. SPIE 10600, Health Monitoring of Structural and Biological Systems XII, 106000G (27 March 2018); doi: 10.1117/12.2294523

Event: SPIE Smart Structures and Materials + Nondestructive Evaluation and Health Monitoring, 2018, Denver, Colorado, United States 


\title{
Silicon Wafer Defect Detection using High Frequency Guided Waves
}

\author{
Michael Lauper ${ }^{\text {a) }}$, Paul Fromme ${ }^{\text {b) }}$, Jean-Luc Robyr ${ }^{\text {a) }}$, and Bernard Masserey ${ }^{\text {a) }}$ \\ a) Department of Mechanical Engineering, University of Applied Sciences and Arts, Fribourg, \\ Switzerland \\ ${ }^{b)}$ Department of Mechanical Engineering, University College London, UK
}

\begin{abstract}
In the photovoltaic industry monocrystalline silicon wafers are employed for the manufacture of solar panels with high conversion efficiency. The cutting process induces micro-cracks on the thin wafer surface. High frequency guided ultrasonic waves are considered for the structural monitoring of the wafers and the nondestructive characterization of the micro-cracks. The material anisotropy of the monocrystalline silicon leads to variations of the wave characteristics depending on the propagation direction relative to the crystal orientation. In non-principal directions of the crystal, wave beam skewing occurs. Selective excitation of the fundamental Lamb wave modes was achieved using a custom-made angle beam transducer and holder to achieve a controlled contact pressure. The out-of-plane component of the guided wave propagation was measured using a noncontact laser interferometer. Artificial defects were introduced in the wafers using a micro indenter with varying loads. The defects were characterized from microscopy images to measure the indent size and combined crack length. The scattering of the $A_{0}$ Lamb wave mode was measured experimentally and the characteristics of the scattered wave field were correlated to the defect size. The detection sensitivity is discussed.
\end{abstract}

Keywords: Monitoring, Silicon, Lamb Wave Modes, Scattering

\section{INTRODUCTION}

Monocrystalline silicon wafers are employed in the photovoltaic industry for the manufacturing of solar panels with high conversion efficiency. The wafer cutting process induces micro-cracks on the surface of the thin and fragile wafers. The drive to increase conversion efficiency and lower manufacturing costs requires thinner wafers, but in practice the minimum wafer thickness is limited by breakage rates [1]. Non-destructive techniques have been developed and tested for the detection of defects in silicon wafers, employing different methodologies such as electro- and photoluminescence imaging, optical transmission and interferometry, thermography, impact testing, and ultrasonic wave propagation $[2,3]$. Guided ultrasonic waves (GUW) $[4,5]$ with long propagation distances and thus area coverage could be used for in-line monitoring of monocrystalline silicon wafers integrated into the manufacturing process. For a structural health monitoring approach using GUW, the detection and localization of defects has been demonstrated $[6,7]$. The detection of hidden damage [8,9] and fatigue cracks [10-13] using high frequency GUW has been investigated. Employing laser excitation and measurement of the fundamental Lamb wave modes, crack detection in silicon wafers was achieved [14]. The amplitude drop of Lamb waves in a B-scan configuration was measured using air-coupled transducers and used to detect cracks in mono-crystalline and poly-crystalline silicon wafers [15]. For crack-like defects, the scattering pattern (and thus detection sensitivity) of GUW depends on the relative crack orientation [16, 17]. The scattering of the fundamental $A_{0}$ mode [18-20] and $S_{0}$ mode [21] at different defects in plates was investigated experimentally and using simulations.

For the anisotropic monocrystalline silicon material, the ultrasonic wave propagation is direction dependent. The energy focusing of ultrasonic waves due to anisotropy has been predicted theoretically and measured experimentally [22, 23] to obtain material properties from an inversion of measurement data [24]. The dependence of the zero group velocity, cutoff frequency, and amplitude on the material orientation was measured using a line laser source [25]. The phase slowness

Health Monitoring of Structural and Biological Systems XII, edited by Tribikram Kundu, Proc. of SPIE Vol. 10600, 106000G · C 2018 SPIE · CCC code: 0277-786X/18/\$18 · doi: 10.1117/12.2294523 
and guided wave beam skew of the fundamental Lamb modes $\left(\mathrm{A}_{0}\right.$ and $\left.\mathrm{S}_{0}\right)$ in a monocrystalline silicon wafer were measured experimentally and compared to theoretical and Finite Element (FE) simulation predictions [26, 27].

The propagation of GUW ( $\mathrm{S}_{0}$ and SH modes) in composite plates and silicon wafers was measured and the variation of arrival time and amplitude with propagation direction quantified [28]. The propagation of GUW in anisotropic, composite plates has been widely studied [29], e.g. the concentration of energy along the stiffer fiber directions [30], the modal focusing [31], and scattering at defects [32].

In this contribution, the scattering of the fundamental $\mathrm{A}_{0}$ guided wave mode at defects in thin monocrystalline silicon wafers was investigated experimentally. The micro-defects were created using an indenter with different forces and measured using a microscope. The scattered GUW field ( $5 \mathrm{MHz}$ center frequency) was measured using a non-contact laser interferometer and analyzed.

\section{EXPERIMENTS}

Measurements were conducted using single crystal silicon wafers with (100) crystallographic orientation. The P-type silicon specimens were boron doped and had a diameter of $100 \mathrm{~mm}(4 \mathrm{inch})$ and nominal thickness of $380 \mu \mathrm{m}$. Nominal cubic symmetric stiffness constants $\left(\mathrm{C}_{11}=165.70 \mathrm{GPa}, \mathrm{C}_{12}=63.90 \mathrm{GPa}, \mathrm{C}_{44}=79.56 \mathrm{GPa}\right)$ were used in Disperse [33] to predict the dispersion diagram and phase slowness curves. Previously, good agreement of measured phase velocities with the theoretical predictions was found [27], showing a variation of the velocities of the fundamental $\mathrm{A}_{0}$ mode by about $3 \%$ between the principal crystal orientations with the highest $<110>$ and lowest $<100>$ stiffness. Due to the anisotropy, a small wave skew of less than $4^{\circ}$ was found for the $\mathrm{A}_{0}$ mode in non-principal crystal directions with good agreements of experiments, FE simulations, and theoretical predictions [26].

The guided waves were generated using a $5 \mathrm{MHz}$ angle beam transducer consisting of a commercial piezoelectric transducer and a custom-made Nylon wedge. The wedge had an angle of $41^{\circ}$, specially adapted to selectively excite the $\mathrm{A}_{0}$ wave Lamb mode at $1.9 \mathrm{MHz} \mathrm{mm}$ (wavelength of approximately $0.8 \mathrm{~mm}$ ). A transducer holder was designed to control the position, orientation and contact force of the angle beam transducer (Fig. 1). A second holder controlled the orientation and position of the silicon wafer, allowing different positions of the excitation location on the silicon wafer (Fig. 2).
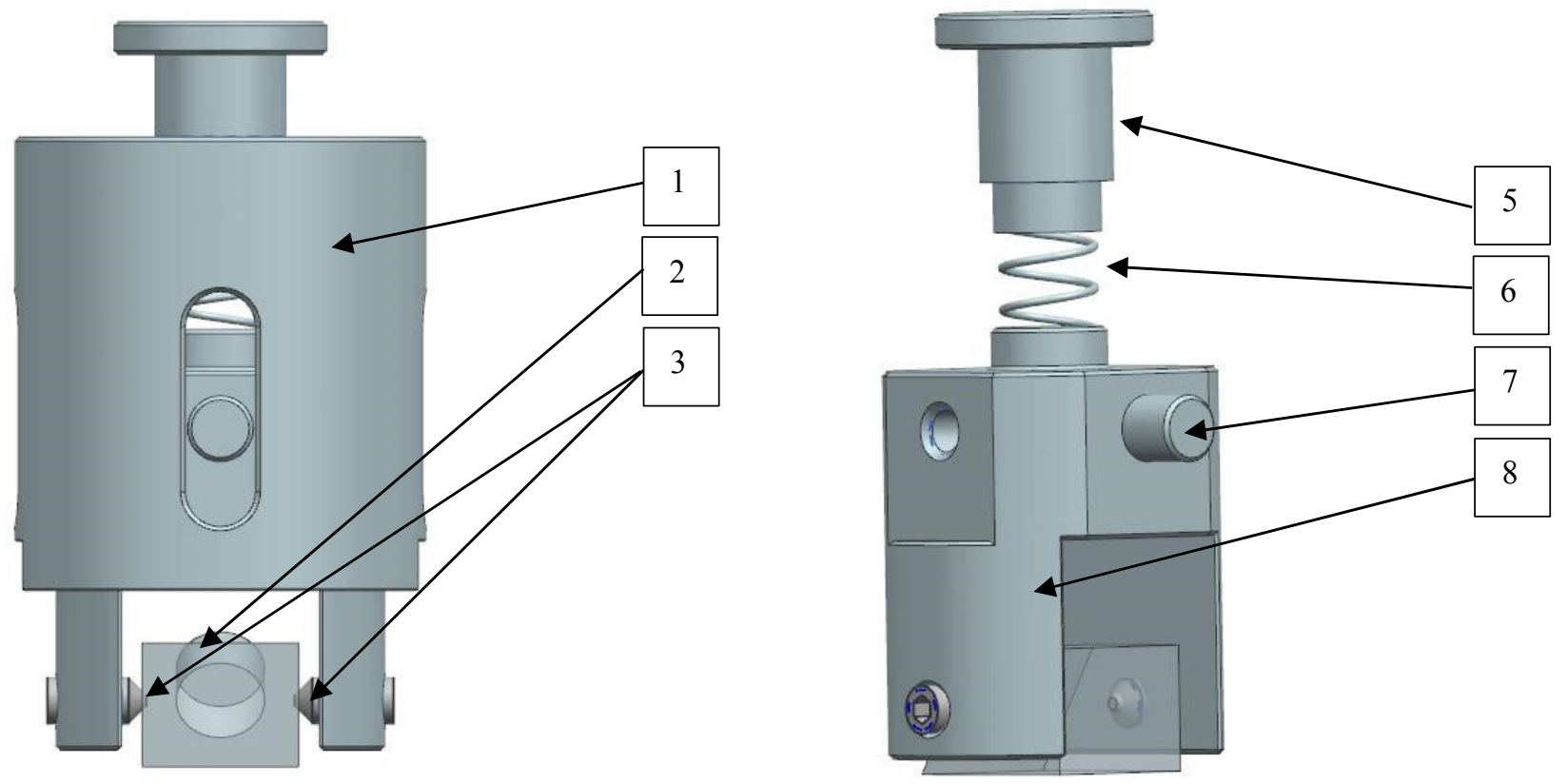

Fig. 1: Design drawing of transducer holder: piston chamber (1), wedge (2), conical screws (3), control force screw (5), compression spring (6), guiding axis (7), piston (8). 


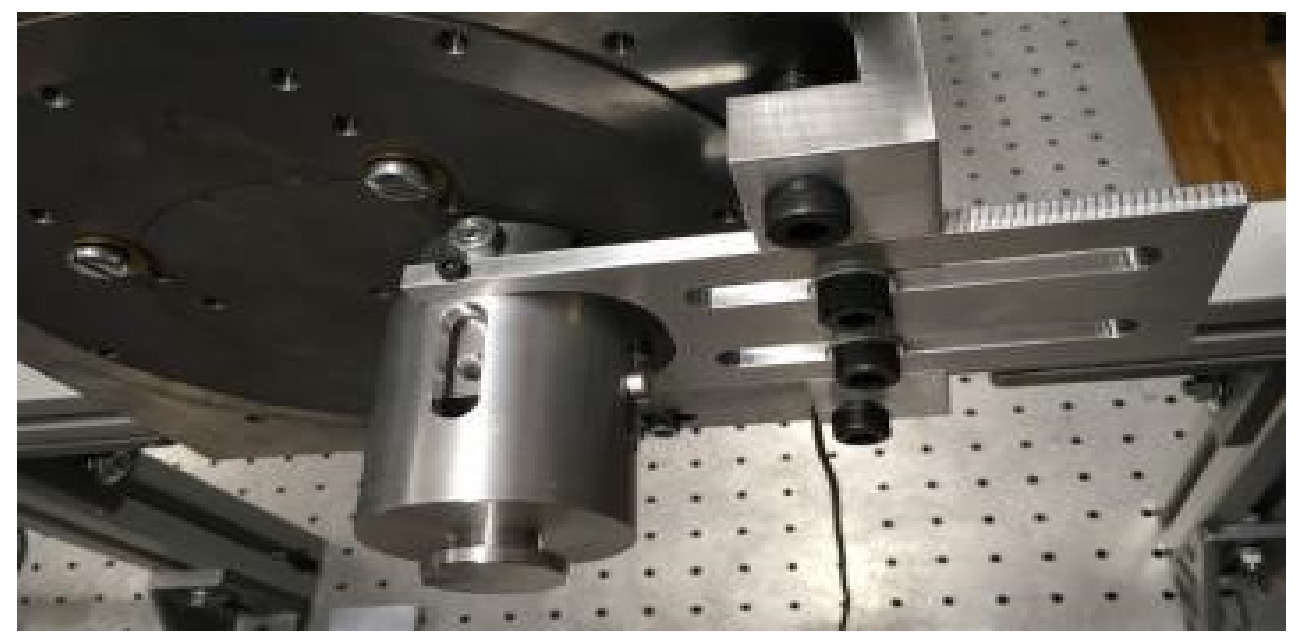

Fig. 2: Experimental setup with wafer and transducer holder.

The excitation signal was created using an arbitrary function generator as a toneburst with $5 \mathrm{MHz}$ center frequency and 12 cycles in a Hanning window. The excitation signal was amplified and applied to the wedge transducer. Measurements were performed using a non-contact laser interferometer, moved parallel to the wafer surface using a scanning rig. The measured signal was band pass filtered ( 2 to $7 \mathrm{MHz}$ ) and averaged (40 averages) using a digital storage oscilloscope for each measurement point. The wedge transducer was oriented to excite the $\mathrm{A}_{0}$ mode with a wave propagation in the principal $\langle 110\rangle$ direction with the highest stiffness. Scan measurements were performed over a $2 \mathrm{D}$ area with a step size of $20 \mu \mathrm{m}$ in both directions. The measurements were evaluated by applying Fast Fourier Transform (FFT) to the time gated signal at every measurement point. The amplitude values at the excitation frequency were extracted and a residual subtraction performed to isolate the scattered field around defects.

\section{CLUSTERED MICRO-DEFECTS}

A monocrystalline silicon wafer was printed with a reference grid as shown in Fig. 3 to allow for the localization of multiple defects. Defects were generated using a Vickers hardness testing machine by making a small indent with a controlled force. This generated micro-cracks from the corners of the indent along the $<110>$ directions of the silicon crystal. The defects were clustered at two locations of the wafer. 9 defects were generated at grid node B3 in a $3 \times 3$ pattern with a spacing of approximately $300 \mu \mathrm{m}$ in both directions. 16 defects were clustered at grid node J8 in a $4 \times 4$ pattern with the same spacing. The force of the indent was varied from $1.5 \mathrm{~N}$ to $3.5 \mathrm{~N}$ in $0.5 \mathrm{~N}$ increments, with multiple indents with the same force. Especially for the higher forces this led to unintended chipping of the brittle silicon next to the indent as shown in the optical microscopy image in Fig. 4a.

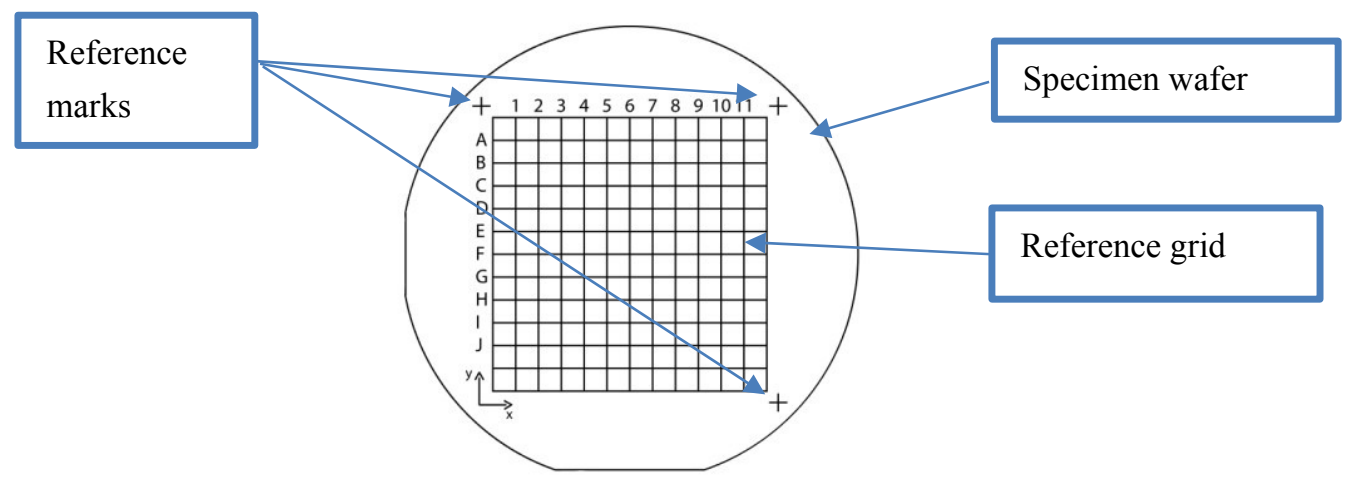

Fig. 3: Wafer with reference grid specifying location of defects (indent and micro-cracks): increment $300 \mu \mathrm{m}$ in $\mathrm{x}-$ and $\mathrm{y}-$ direction between indents, clustered as $3 \times 3$ (grid node B3) and $4 \times 4$ (grid node J8), force varied from $1.5 \mathrm{~N}$ to $3.5 \mathrm{~N}$ in $0.5 \mathrm{~N}$ increments. 

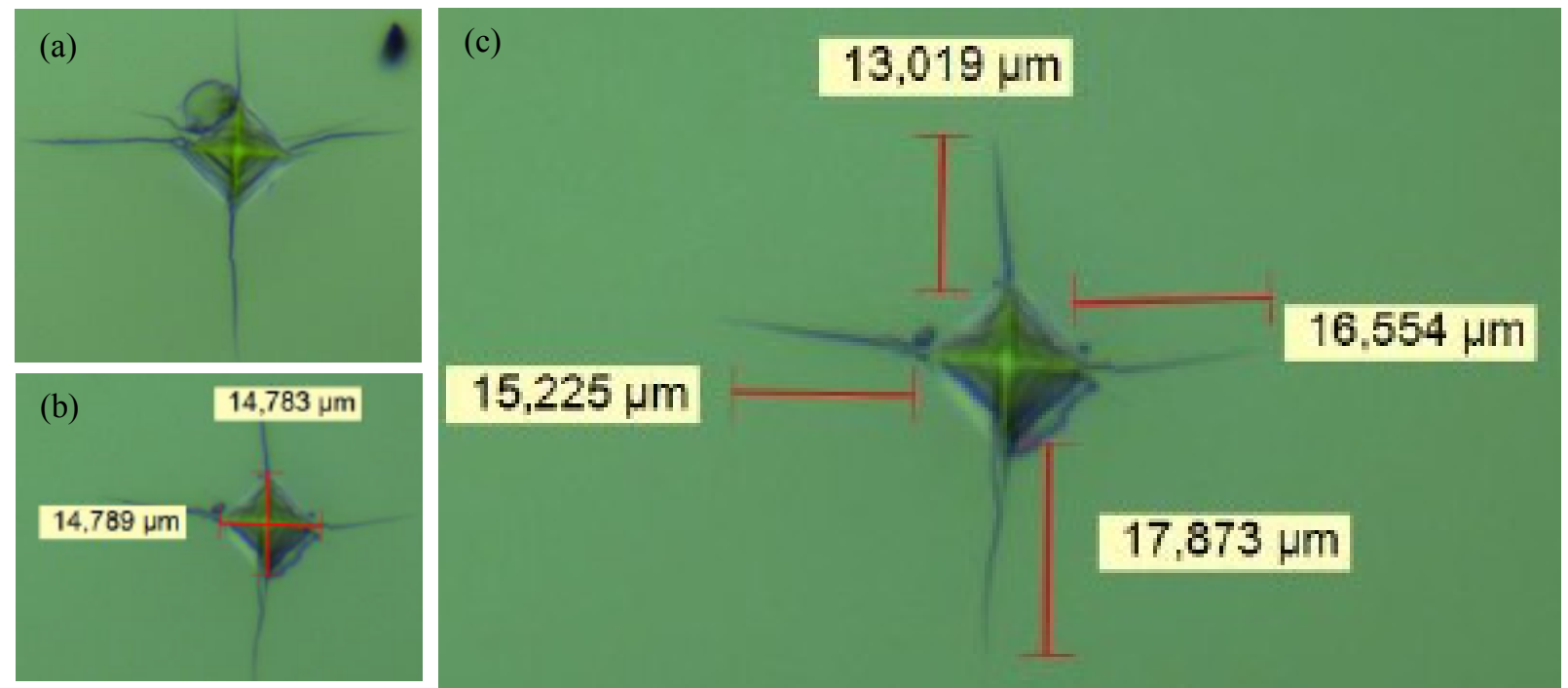

Fig. 4: Microscopy image of defects: (a) indent with chipping; (b) indent ( $2 \mathrm{~N}$ force) with measurement of diagonals; (c) measurement micro-cracks from indent corners along $<110>$ crystallographic directions.

For all of the generated defects, the diagonal size of the indent and the four micro-cracks emanating from the corners were measured using an optical microscope. A typical image of one defect is shown in Fig. 4b/c with the measured lengths superimposed on the microscopy image. The size of the indents and overall defect length (length of 2 cracks and indent diagonal) was recorded and is shown in Fig. 5. Figure 5 shows the respective lengths in the horizontal and vertical directions and the linear fit for indent and overall size. For indent forces up to $2.5 \mathrm{~N}$, limited variation of the defect size and an increase with indent force can be observed. For the largest force of $3.5 \mathrm{~N}$ an increased variation of the overall defect length can be observed. This is likely due to the observed chipping of the wafer at this higher force.

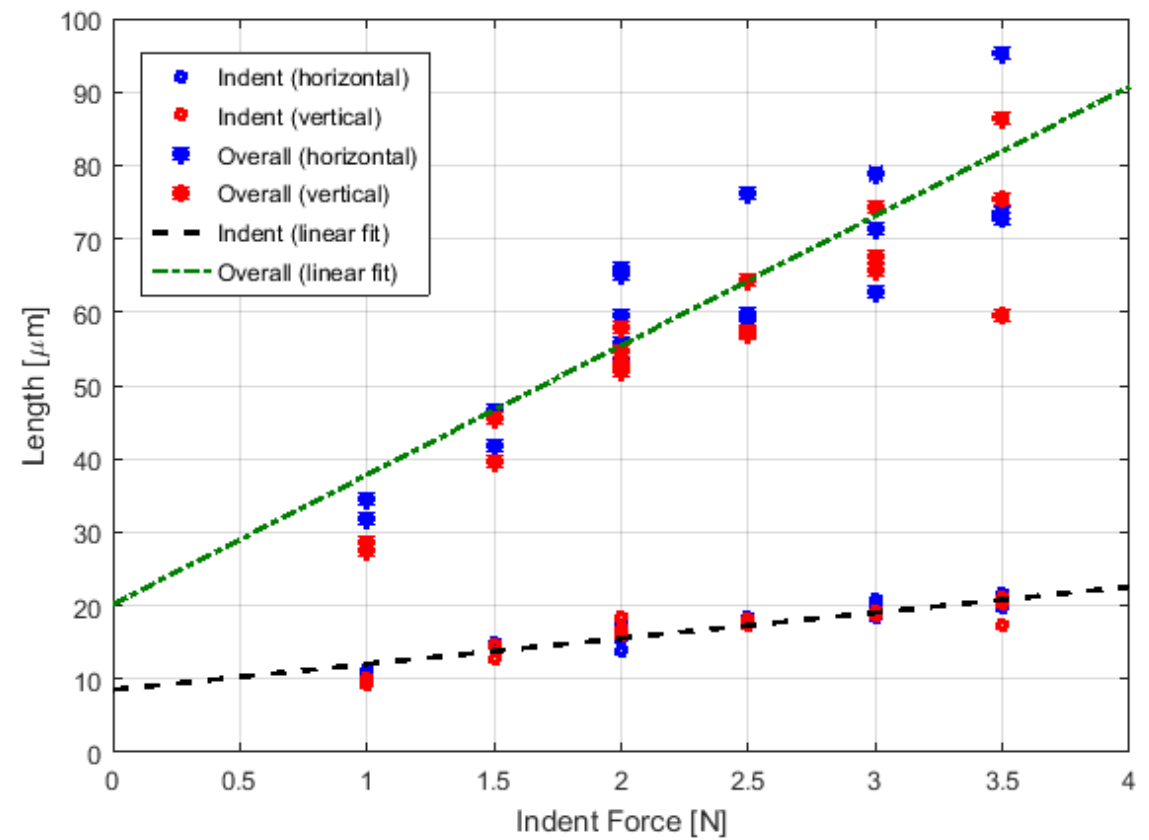

Fig. 5: Indent size and overall defect length (indent and micro-cracks length) for variation of indent force; horizontal and vertical length and linear fit for indent and overall length. 
(a)

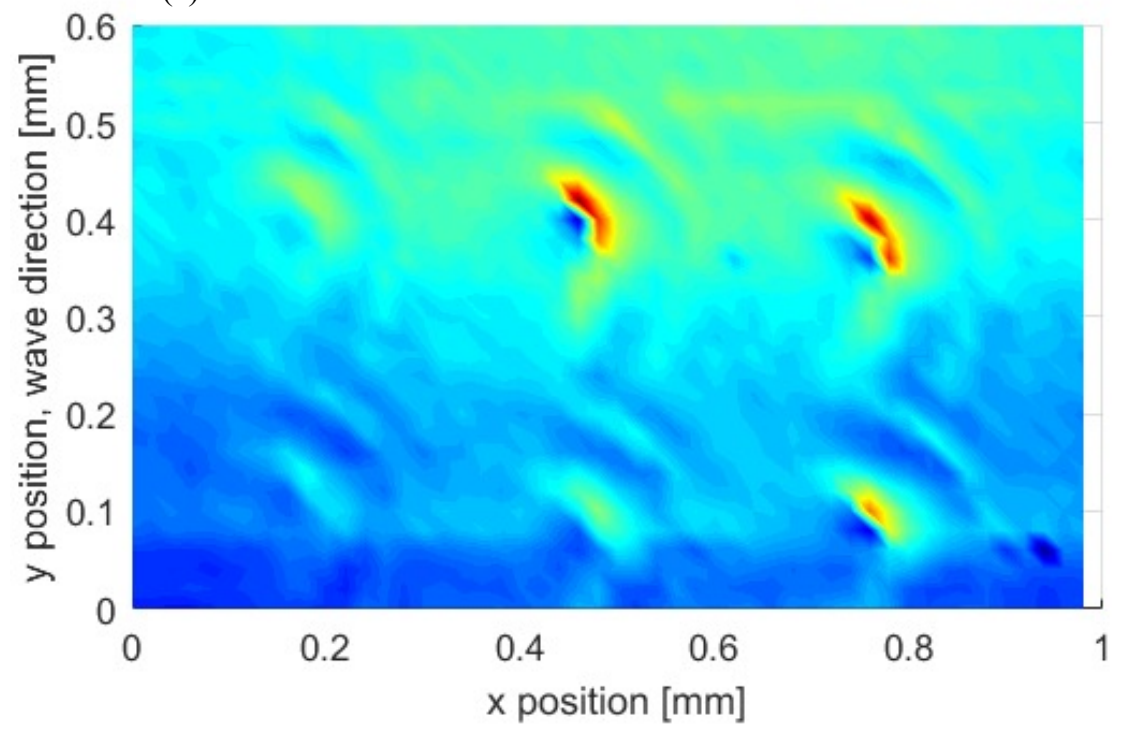

(b)

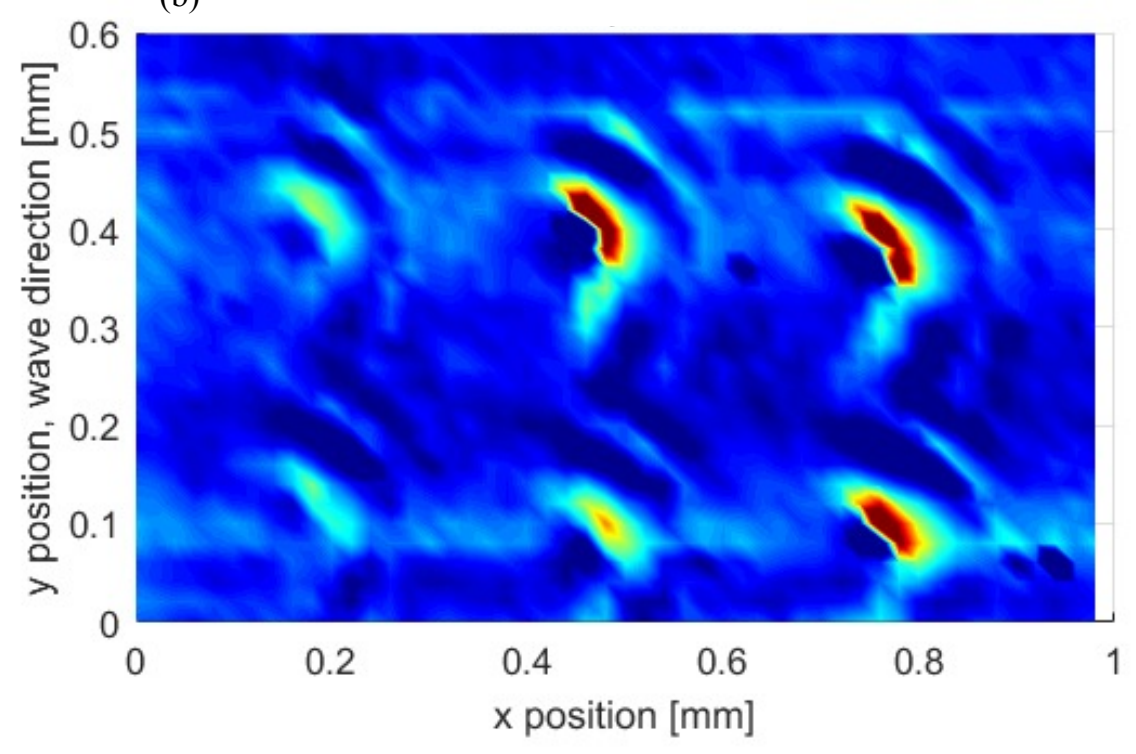

Fig. 6: Amplitude of guided wave scattered field ( $\mathrm{A}_{0}$ mode, $5 \mathrm{MHz}$ center frequency) around clustered defects (indents and micro-cracks); indent force $1 \mathrm{~N}(\mathrm{x}=0.2 \mathrm{~mm}), 1.5 \mathrm{~N}(\mathrm{x}=0.5 \mathrm{~mm}), 2 \mathrm{~N}(\mathrm{x}=0.8 \mathrm{~mm})$ : (a) measured amplitude (FFT); (b) amplitude after removal of residual. 
(a)
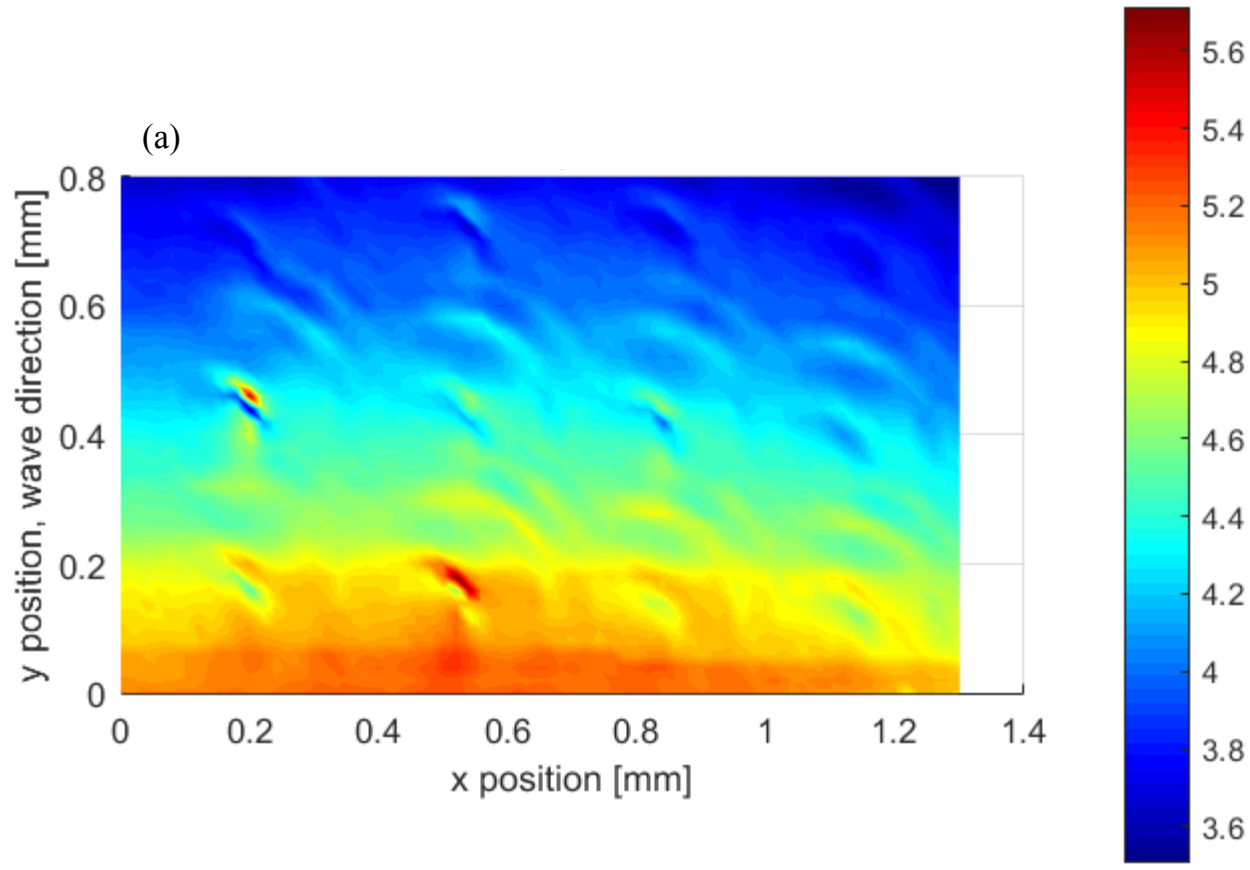

5.4

5.2

4.8

4.6

4.4

4.2

3.6

0.25

(b)

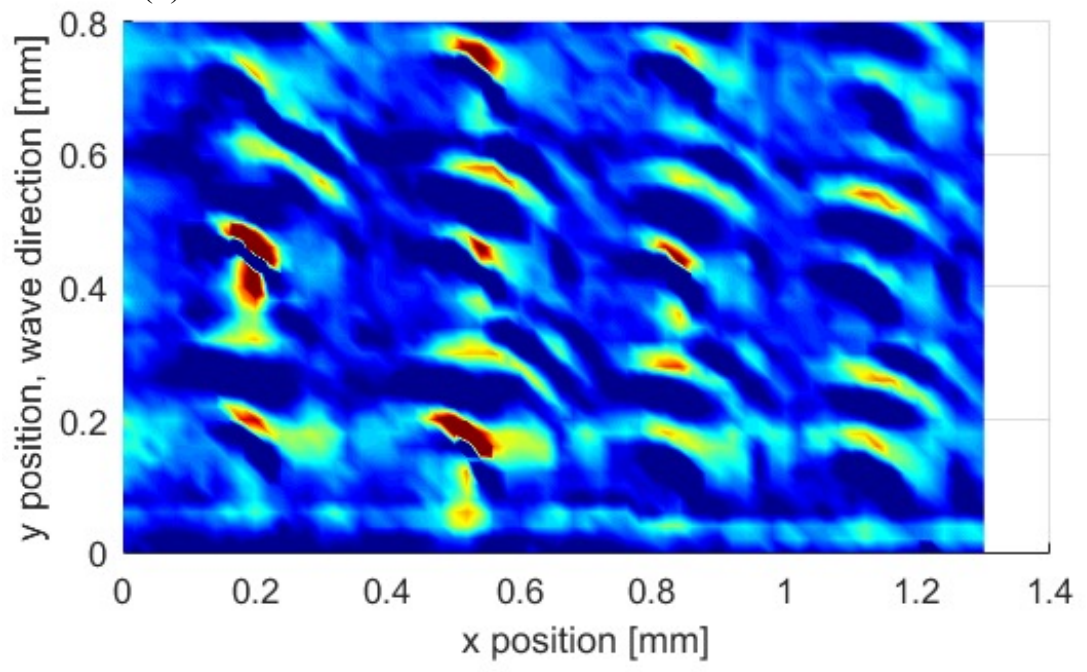

Fig. 7: Amplitude of guided wave scattered field $\left(\mathrm{A}_{0}\right.$ mode, $5 \mathrm{MHz}$ center frequency) around clustered defects (indents and micro-cracks); indent force $3.5 \mathrm{~N}(\mathrm{x}=0.2 \mathrm{~mm}), 3 \mathrm{~N}(\mathrm{x}=0.5 \mathrm{~mm}), 2.5 \mathrm{~N}(\mathrm{x}=0.8 \mathrm{~mm}), 2 \mathrm{~N}(\mathrm{x}=1.1 \mathrm{~mm}):($ a) measured amplitude (FFT); (b) amplitude after removal of residual. 


\section{GUW SCATTERED FIELD}

The scattered guided ultrasonic wave field around the clustered defects was measured as described above on a 2D grid with a spacing of $20 \mu \mathrm{m}$ in both directions. For each measurement point, the amplitude at the center frequency of $5 \mathrm{MHz}$ was extracted using FFT and is shown color-coded in Figs. 6a and 7a for an incident wave direction from the top. Scattering at the individual defects, but also an overall variation of the amplitude due to the incident guided wave beam can be observed. Using Matlab, a residual subtraction of the incident wave field was performed to isolate the variations in amplitude around the defects, shown in Figs. $6 \mathrm{~b}$ and $7 \mathrm{~b}$. In Fig. $6 \mathrm{~b}$, the scattering at the 6 individual defects (consisting of indent and 4 micro-cracks) in the measurement area can be seen, with defects spaced approximately 0.3 $\mathrm{mm}$ apart. The maximum amplitude of the scattered field increase in general with indent force and thus overall defect size from the defects at $0.2 \mathrm{~mm}$ (x position) with indent force $1 \mathrm{~N}$ to the defects at $0.8 \mathrm{~mm}$ with indent force $2 \mathrm{~N}$. It should be noted that the scattered amplitude field is not symmetric to the incident wave direction (propagation along y axis), but appears to have an orientation of approximately 45 degrees. More detailed investigation should ascertain whether this effect is repeatable and due to the defect configuration or related to the anisotropy. Fig. $7 \mathrm{~b}$ shows the scattered amplitude field around the clustered defects with larger indent force ranging from 2 to $3.5 \mathrm{~N}$. Again a general correlation of the scattered amplitude with indent force and thus overall defect size can be seen, but more variation of the scattered amplitude field around individual defects was observed. For the larger indent force, increased chipping of the silicon wafer next to the indent occurred, which has an effect on the guided wave scattering and should be investigated further.

\section{CONCLUSIONS}

The scattering of guided waves at defects in monocrystalline silicon wafers was studied experimentally. The fundamental $\mathrm{A}_{0}$ Lamb wave mode was excited selectively at a center frequency of $5 \mathrm{MHz}$ using a contact wedge transducer. The scattered field around clustered defects was measured using a non-contact laser interferometer. Defects were generated using a Vickers hardness testing machine, which generated an indent and localized micro-cracks in the silicon wafer. The defect size was quantified from microscopy images and overall showed a good correlation with indent force. For larger indent forces, chipping of the silicon wafer and increased variation of the overall damage size was observed. The scattered wave field showed scattering at all measured defects, including the smallest defects with an overall extent of less than $40 \mu \mathrm{m}$ (wavelength to defect size of approximately 20). A correlation of scattered wave field amplitude with indent force and thus defect size was observed, but more quantification will be required. In principle, the sensitivity of guided ultrasonic waves for small surface defects in silicon wafers was demonstrated, setting the basis for further research to enable the monitoring of the wafers during the manufacturing process.

\section{REFERENCES}

[1] Luque, A. and Hegedus, S., [Handbook of Photovoltaic Science and Engineering], Wiley, New York (2011).

[2] Abdelhamid, M., Singh, R. and Omar, M., "Review of microcrack detection techniques for silicon solar cells," IEEE J. Photovoltaics 4, 514-524 (2014).

[3] Israil, M., Ghani, A. and Kerm, Y., "Non-destructive microcracks detection techniques in silicon solar cell," Phys. Sci. Int. J. 4, 1073-1087 (2014).

[4] Rose, J.L., "Standing on the shoulders of giants: An example of guided wave inspection," Mat. Eval. 60, 53-59 (2002).

[5] Fromme, P., "Monitoring of plate structures using guided ultrasonic waves," AIP Conf. Proc. 975, 78-85 (2008).

[6] Fromme, P., "Health monitoring of plate structures using guided waves," Proc. SPIE 6935, 69350W (2008).

[7] Hall, J.S., Fromme, P. and Michaels, J.E., "Guided wave damage characterization via minimum variance imaging with a distributed array of ultrasonic sensors," J. Nondestruct. Eval. 33, 299-308 (2014).

[8] Masserey, B., Raemy, C. and Fromme, P., "High-frequency guided ultrasonic waves for hidden defect detection in multi-layered aircraft structures," Ultrasonics 54, 1720-1728 (2014).

[9] Chan, H., Masserey B. and Fromme, P., "High frequency guided ultrasonic waves for hidden fatigue crack growth monitoring in multi-layer model aerospace structures," Smart Mater. Struct. 24, 025037 (2015).

[10] Masserey, B. and Fromme, P., "Analysis of high frequency guided wave scattering at a fastener hole with a view to fatigue crack detection," Ultrasonics 76, 78-86 (2017). 
[11] Masserey, B. and Fromme, P., "In-situ monitoring of fatigue crack growth using high frequency guided waves," NDT\&E Int. 71, 1-7 (2015).

[12] Masserey, B. and Fromme, P., "In-situ monitoring of fatigue crack growth at fastener holes using Rayleigh-like waves" AIP Conf. Proc. 975, 1484-1491 (2008).

[13] Kostson, E. and Fromme, P., "Fatigue crack growth monitoring in multi-layered structures using guided ultrasonic waves," J. Phys.: Conf. Ser. 195, 012003 (2009).

[14] Song, M.-K. and Jhang, K.-Y., "Crack detection in single-crystalline silicon wafer using laser generated Lamb wave," Adv. Mater. Sci. Eng. 2013, 950791 (2013).

[15] Chakrapani, S.K., Padiyar, M.J. and Balasubramaniam, K., "Crack detection in full size Cz-silicon wafers using lamb wave air coupled ultrasonic testing (LAC-UT)," J. Nondestruct. Eval. 31, 46-55 (2012).

[16] Rouge, C. and Fromme, P., "Directivity of guided ultrasonic wave scattering at notches and cracks," J. Phys.: Conf. Ser. 269, 012018 (2011).

[17] Fromme, P., "Influence of guided ultrasonic wave scattering directionality on the detection sensitivity for SHM of fatigue cracks," Proc. SPIE 7650, 76501M (2010).

[18] Lowe, M.J.S., Cawley, P., Kao, J.Y. and Diligent, O., "The low frequency reflection characteristics of the fundamental antisymmetric Lamb wave a0 from a rectangular notch in a plate," J. Acoust. Soc. Am. 112, 2612-2622 (2002).

[19] Fromme, P. and Sayir, M.B., "Measurement of the scattering of a Lamb wave by a through hole in a plate," J. Acoust. Soc. Am. 111, 1165-1170 (2002).

[20] Pao, Y.H. and Chao, C.C., "Diffractions of flexural waves by a cavity in an elastic plate," AIAA J. 2, 2004-2010 (1964).

[21] Diligent, O., Grahn, T., Bostrom, A., Cawley, P. and Lowe, M.J.S., "The low-frequency reflection and scattering of the S0 Lamb wave mode from a circular through-thickness hole in a plate: Finite Element, analytical and experimental studies," J. Acoust. Soc. Am. 112, 2589-2601 (2002).

[22] Maris, H.J., "Enhancement of heat pulses in crystals due to elastic anisotropy," J. Acoust. Soc. Am. 50, 812-818 (1971).

[23] Kim, K.Y., Bretz, K.C., Every, A.G. and Sachse, W. "Ultrasonic imaging of the group velocity surface about the cubic axis in silicon,” J. Appl. Phys. 79, 1857-1863 (1996).

[24] Audoin, B., Bescond, C. and Deschamps, M., "Measurement of stiffness coefficients of anisotropic materials from pointlike generation and detection of acoustic waves," J. Appl. Phys. 80, 3760-3771 (1996).

[25] Prada, C., Clorennec, D., Murray, T.W. and Royer, D., "Influence of the anisotropy on zero-group velocity Lamb modes," J. Acoust. Soc. Am. 126, 620-625 (2009).

[26] Fromme, P., Pizzolato, M., Robyr, J.-L. and Masserey, B., "Lamb wave propagation in monocrystalline silicon wafers," J. Acoust. Soc. Am. 143, 287-295 (2018).

[27] Pizzolato, M., Masserey, B., Robyr, J.-L. and Fromme, P., "High frequency guided wave propagation in monocrystalline silicon wafers," Proc. SPIE 10170, 101702B (2017).

[28] Veidt, M. and Sachse, W., "Ultrasonic point-source/point-receiver measurements in thin specimens," J. Acoust. Soc. Am. 96, 2318-2326 (1994).

[29] Murat, B.I.S., Khalili, P. and Fromme, P., "Scattering of guided waves at delaminations in composite plates," J. Acoust. Soc. Am. 139, 3044-3052 (2016).

[30] Leleux, A., Micheau, P. and Castaings, M., "Long range detection of defects in composite plates using Lamb waves generated and detected by ultrasonic phased array probes," J. Nondestruct. Eval. 32, 200-214 (2013).

[31] Chapuis, B., Terrien, N. and Royer, D. "Excitation and focusing of Lamb waves in a multilayered anisotropic plate," J. Acoust. Soc. Am. 127, 198-203 (2010).

[32] Endrizzi, M., Murat, B.I.S., Fromme, P. and Olivo, A., "Edge-illumination X-ray dark-field imaging for visualising defects in composite structures," Compos. Struct. 134, 895-899 (2015).

[33] Pavlakovic, B., Lowe, M. J. S., Alleyne, D. and Cawley, P., "Disperse: A general purpose program for creating dispersion curves," Proc. QNDE 16, 185-192 (1997). 